\section{UM OLHAR PSICANALÍTICO SOBRE A VIGOREXIA}

\section{A Psychoanalytic Look about Muscle Dysmorphia \\ Una Mirada Psicoanalitica sobre la Dismorfia Muscular
(Vigorexia)}

Un Regard Psychanalytique sur la Musculaire Dysmorphie

\begin{abstract}
Resumo
O artigo trata de um dos tipos de transtorno dismórfico corporal, popularmente conhecido como dismorfia muscular ou "vigorexia". Pretende tentar compreender sua etiologia por meio da teoria psicanalítica freudo-lacaniana. Assim verificamos que o isolamento desse conjunto de sintomas pela psiquiatria com pretensões de fundar no DSM (Manual de Diagnóstico e Estatística das Perturbações Mentais) um novo transtorno, na verdade está relacionado à discordância fundamental do sujeito com a imagem. Analisa-se ainda, no artigo, a relação do sujeito com castração, o complexo de Édipo, a sexuação e os ideais de corpo da contemporaneidade, bem como se demonstra que a vigorexia é um sintoma que emerge como resposta do sujeito ao mal-estar na cultura contemporânea.
\end{abstract}

Palavras-chave: vigorexia; sintomas; gozo; imagem de corpo; psicanálise.

\section{Abstract}

The article deals with a type of body dysmorphic disorder, popularly known as "muscle dysmorphia". Intends to try understand its etiology through the freudian-lacanian psychoanalytic theory. Thus we find that the isolation of this set of symptoms in psychiatry with pretensions to create in the DSM (Diagnostic and Statistical Manual of Mental Disorders) a new disorder, is actually related to the subject's fundamental disagreement with his body image. Further, it is analyzed the subject's relation to castration, the Oedipus complex, the sexuation, and the contemporary body ideals, as well as demonstrates that muscle dysmorphia is a symptom of the subject that emerges as a response to the malaise in contemporary culture.

Keywords: muscle dysmorphia; symptoms; enjoyment; body image; psychoanalysis.

\section{Resumen}

El artículo trata de un tipo de trastorno dismórfico corporal, popularmente conocido como dismorfia muscular o "vigorexia". Tiene la intención de tratar de entender su etiología a través de la teoría psicoanalítica freud-lacaniana. Asi nos encontramos con que el aislamiento de este conjunto de síntomas en psiquiatría con pretensiones de fundar en el DSM (Manual Diagnóstico y Estadístico de los Trastornos Mentales) un nuevo desorden, está realmente relacionado con el desacuerdo fundamental con la imagen de cuerpo del sujeto. Se analiza más en el artículo, la relación del sujeto con la castración, el complejo de Edipo, la sexuación y los ideales de la contemporánea, así como demuestra que la vigorexia es un sintoma de que el tema surge como una respuesta al malestar en la cultura contemporánea.

Palabras clave: vigorexia; sintomas; goce; imagen corporal; psicoanálisis.

\section{Résumé}

L'article traite d'un type de la dysmorphie corporelle, populairement connu comme le musculaire dysmorphie ou "bigorexia". Avoir l'intention d'essayer de comprendre son étiologie par la théorie psychanalytique freudienne-lacanienne. Ainsi nous constatons que l'isolement de cet ensemble de symptômes en psychiatrie avec des prétentions à fonder dans le
Artigo Original

\section{Odimar A. Feitosa Filho ${ }^{(1)}$}

1) Psicanalista. Mestre em Psicologia pela Universidade Federal do Ceará. Professor Assistente do Curso de Psicologia da Universidade Federal do Ceará-Sobral.
Recebido em: 15/03/2012 Revisado em: 08/04/2014 Aceito em: 22/09/2014 
DSM (Manuel Diagnostique et Statistique des Troubles Mentaux) un nouveau désordre, est en fait lié au désaccord fondamental du sujet avec son image. Il est analysé, plus loindans, la relation du sujet à la castration, le complexe d'Edipe, la sexuation et les idéaux du corps de la contemporanéité ainsi que démontre que le dysmorphie musculaire est un symptôme du sujet que apparaît comme une réponse au malaise dans la culture contemporaine.

Mots-clés: dysmorphie musculaire; symptômes; joissence; l'image du corps; psychanalyse.

Seguindo o caminho desbravado por Freud (1908/2011d) o psicanalista deve estar atento aos sinais de seu tempo, à moral sexual nele presente, uma vez que esta se relaciona com os ideais culturais e com a formação de sintomas. Nesse sentido, este artigo, de cunho bibliográfico desenvolve problemas apontados em Pesquisas anteriores (Feitosa Filho, 2008) sobre as discursividades desses sujeitos coletadas na plataforma virtual Orkut. Essa metodologia está referendada em trabalhos psicanalíticos como na análise que Freud (1911/1996) estabeleceu partindo da leitura das memórias do "Presidente Schereber". Considera-se, pois, que mesmo nunca tendo atendido o mesmo, é possível analisar os sintomas e os modos de gozo presentes no relato e aguardar que a clínica de outros sujeitos possa referendar ou refutar as hipóteses levantadas. É desta forma que se procedeu na retomada dessa problemática: foram analisados alguns sintomas da vigorexia em sua articulação com o malestar na cultura e os modos de gozo propondo hipóteses especulativas, ou ficções metapsicológicas que possam pensar os sintomas vigoréxicos no homem contemporâneo.

Para estabelecer um olhar sobre a dismorfia muscular (vigorexia), definiu-se a proposição deste transtorno pela psiquiatria e, em seguida utilizou-se do referencial psicanalítico freudo-lacaniano para compreender a etiologia, a formação dos sintomas vigoréxicos relacionando esta ao mal-estar na cultura presente nos laços sociais.

\section{Do Surgimento de um "Ideal de Corpo" à Proposição de um "Transtorno" na Contemporaneidade}

A contemporaneidade produziu novos "cuidados de si" manifestos pelo culto à beleza, juventude do corpo e pela ideia de que este pode ser remodelado de acordo com o desejo de cada um. Este culto à forma do corpo tem investido principalmente sob dois aspectos: aumento da musculatura e definição corporal. A "cultura do corpo" está ligada em suas origens a uma ética puritana do trabalho que floresceu e se difundiu a partir dos Estados Unidos, impulsionada pelo surgimento de uma sociedade de consumo em massa onde, conforme aponta Baudrillard (1970), o corpo pode ser investido como "o mais belo objeto de consumo". Numa leitura similar, Courtine (2004), aponta que entre os séculos XIX e XX surgiu um ideário em torno da obtenção de um corpo mais forte e saudável, promovendo também mudanças psicológicas. A sociedade de consumo gerou imperativos culturais difundidos pela denominada "cultura pós-moderna", massificada sob a égide de um american way of living.

Foi no cerne da cultura hodierna que o psiquiatra ianque Harrison G. Pope Jr (1993), da Universidade de Harvard, descreveu pela primeira vez um transtorno observado em indivíduos praticantes de musculação. $\mathrm{Na}$ amostra do estudo, foi constatado que alguns indivíduos se consideravam demasiadamente fracos e pequenos quando na verdade eram bastante fortes e musculosos, caracterizando uma distorção na imagem de corpo. Neste trabalho o autor chama atenção para as dificuldades que envolveram a Pesquisa, dentre elas aponta o fato de que muitos indivíduos podem ter esse transtorno, mas sentem vergonha de expor e dificilmente chegam a buscar algum tipo de atendimento. Ballone (n.d.), afirma que vários autores não consideram a vigorexia uma nova doença ou entidade clínica independente, e sim como manifestação clínica do Transtorno Dismórfico Corporal. Essa manifestação separada seria o Transtorno Dismórfico Muscular ou vigorexia. Autores como Pope (2000), Vasconcelos (2013) afirmam que a criação dessa categoria nosográfica aponta causas genéticas, cobranças sociais, influência da mídia, tendo uma prevalência maior no sexo masculino. Os sintomas da vigorexia se situam em torno da preocupação exacerbada do individuo com a aparência do corpo. Segundo as Pesquisas Pope, Philips e Olivardia (1993) 78\% dos homens se mostram insatisfeitos com o próprio corpo, seja com o abdômen, o peso corporal, o tônus muscular ou o tórax. A vigorexia é uma percepção distorcida da imagem de corpo que se caracteriza pela busca incessante de aumento da massa muscular e sua definição, consumo de dietas especificas suplementos vitamínicos, esteróides e anabolizantes, além da prática excessiva de exercícios físicos desconsiderando os riscos que podem causar.

$\mathrm{O}$ século XX foi aquele em que se intensificaram a visibilidade e a capacidade de intervir sobre o corpo, reforçado por uma nova sensibilidade da qual fez parte o espírito competitivo e o desejo de vencer, visto como um sucesso da vontade própria e êxito da aplicação ao trabalho, demonstrando a eficácia do eu obtida pela autodisciplina. Esse superinvestimento na aparência e, sobretudo, na aparência do corpo aparece como uma substituição do corpo-ferramenta para o corpo-consumidor.

Baseada no conceito de hipermodernidade, Severiano 
(2010) aponta que as características da modernidade se tornaram hiperlativas, baseadas no triunfo do excesso, produzindo um hiperconsumo, hiperindividualismo, hipercorpo, etc. Entretanto essa cultura "hiper" convive lado a lado com o suposto paradoxo da moderação que, na reflexão da autora, apontaria muito mais para modos de dominação e controle.

Referendados na Psicanálise freudo-lacaniana, em conceitos como narcisismo, imagem de corpo, gozo e malestar na cultura objetiva-se neste estudo apresentar uma teorização capaz de compreender a causalidade vigorexia e a relação destes indivíduos com seus sintomas enquanto sujeito.

\section{A Relação do Sujeito com o Falo nos Sintomas Vigoréxicos}

Pensar a relação do indivíduo com sintomas vigoréxicos com a imagem requer, inicialmente, seguirmos as considerações lançadas por Freud, Lacan e seus seguidores e lançar hipóteses para compreendermos a relação entre o sujeito $(\$)$ e a libido a partir do conceito de falo $(\varphi)$.

O falo representa o valor da libido investida nos objetos e articula narcisismo, Édipo, castração e sexuação. Com a introdução do conceito de estádio do espelho, Lacan (1966/1988) desenvolve uma teorização que em muito ampliou os estudos sobre o narcisismo, asseverando que o corpo, inicialmente descoordenado, despedaçado e impotente do bebê é reunido numa forma, uma Urbild; essa conquista promove uma satisfação narcísica, resultando desta, uma fascinação na qual o sujeito encontra sua unidade jubilatória onde a forma do corpo é vista como perfeita e amável, havendo aí uma captura da libido no imaginário. Ocorre que a conquista antecipada dessa unidade por meio das percepções é percebida do lado de fora, no Outro, mas de fato, o bebê vivencia ainda um momento de impotência e imperícia discordantes com a perfeição desta unidade jubilatória. O segredo da jubilação é o encobrimento da falta, na medida em que esta imagem aparece como Gestalt completa, levando o sujeito a regozijar-se na completude. "O gozo da imagem dá razão a essa posição subjetiva de fazer-se com seu narcisismo, de objeto de desejo do outro, dando a impressão de não ter falta de nada." (Quinet, 2002, p. 134). É nesse momento fundante que o indivíduo com sintomas vigoréxicos parece ancorado, no entanto, essa experiência de discordância fundamental - entre a imagem ideal e a realidade - faz parte da condição humana, uma vez que a relação de qualquer indivíduo, vigoréxico ou não, com a imagem não se achará nunca efetivada.

Nos Escritos (1966/1998), Lacan aponta que o falo concentra o mais íntimo do autoerotismo e, mais tarde, ao desenvolver o conceito de objeto a (1966/1988) o define como objeto condensador de gozo, mas não cansa de lembrar que toda relação com o gozo passa pela proibição tornando-o inalcançável no ser falante. É pela travessia do complexo de Édipo e a interdição do incesto que o sujeito entra na ordem da cultura. Inicialmente há uma relação narcísica fusional entre a criança e a mãe, não havendo, por parte da criança, distinção entre o si e o outro. Nesse momento, a criança se constitui como objeto capaz de satisfazer o desejo da mãe, identificando-se imaginariamente com o falo. Entretanto essa relação porta uma alienação fundamental para o bebê, tomado como objeto, que faz surgir a agressividade fundamental como tentativa de romper esta relação na qual o bebê se encontra capturado pelo desejo do outro. A tentativa de romper essa alienação é situada como desejo de reconhecimento. Nesse primeiro tempo, a criança está na dialética do ser ou não ser o falo, objeto do desejo para a mãe. Aí se colocam dois pontos: o eu e esse outro (imagem ideal) formada do lado de fora, aquilo com que a criança busca se identificar para satisfazer a mãe. Ora, estamos aqui no campo do Eu Ideal, em que a criança acredita que, para satisfazer a mãe, precisa identificar-se com aquilo que the falta: o falo. Assim todas as identificações presentes nesse momento do narcisismo primário remeterão à onipotência e à perfeição.

A partir do momento em que, no discurso da mãe, o pai assume certa consistência capaz de mobilizar seu desejo, ele começa a aparecer para a criança como um terceiro na relação narcísica dual. A criança entra num momento de incerteza psíquica que a faz se confrontar com a incompletude, forçando-a a aceitar a ideia de que ela não é tudo para essa mãe, e que algo já estava ali, antes dela, mobilizando o desejo materno, eis a incidência da castração. Essa sensação de incompletude conclama a criança a buscar se identificar com traços da cultura, para que possa, novamente, se fazer amada pelo Outro. A assunção dessa operação estruturante que é a castração $(-\varphi)$ se dá por meio da travessia do complexo de Édipo:

A sexualidade, com suas disposições polimorfas, com seus componentes sexuais "perversos", com sua multiplicidade originária de zonas e objetos foi, depois deste processo arrasada. Ai onde o gozo se derramava de modo anárquico no verde paraíso dos amores infantis tem agora uma lei, efeito da castração e da proibição do incesto, que determina os objetos e os modos de satisfação acessíveis àquele que fala. (Braunstein, 2007, p.70)

O falo é o significante da diferença sexual, entretanto não há representação psíquica inconsciente da diferença anatômica entre os sexos, mas há a representação do falo. $\mathrm{Na}$ organização genital infantil, "[...] para os dois sexos, um único órgão genital, o órgão masculino, desempenha um 
papel. Não existe, portanto, um primado do genital, mas um primado do falo." (Freud, 1923/1996e, p. 114). O falo apresenta uma relação com o pênis, pois, para a criança, é sob a forma de pênis que uma parte do corpo será percebida como presença ou ausência; essa é a função do falo imaginário. Do lado simbólico, a linguagem virá permitir ao sujeito as inscrições simbólicas que posicionarão cada um no campo do masculino ou do feminino. A função fálica ordena os possíveis modos de sexuação do sujeito, trazendo o problema de saber como será significado o sexo biológico. $\mathrm{O}$ real do sexo por si só não basta, pois podem ser dadas diferentes significações ao dado anatômico, mas é sobre esse real do corpo que incide a significação fálica em torno da qual se ordena o complexo de Édipo. Isso quer dizer que no lugar onde havia o gozo, este deve passar pelo significante.

A castração implica para o sujeito sempre uma perda de gozo. Nesse sentido, meninos e meninas se posicionam de forma diferenciada, pois, se a anatomia oferece ao menino a ilusão do ter, na menina falta, no real do corpo, algo que forneça uma significação sexual diferente daquela da castração. Assim, no caso do menino, a anatomia é capaz de sustentar a ilusão do ter o falo, muito embora esse seja ameaçado, fazendo surgir a angústia, que revela o temor da perda. A travessia do complexo de Édipo se processa sob a lógica da castração, de forma que o sujeito não pode ocupar esse lugar de complemento para da falta da mãe (Eu ideal). A interdição dessa relação incestuosa e o reconhecimento que há um limite para o campo do desejo efetuada pela castração fará individuo renunciar ao gozo, embora este faça sempre uma exigência de retorno ao sujeito. Os investimentos libidinais que eram dirigidos aos pais são interditados e a formação moral do Supereu vai implicar numa dessexualização destes, que marcará o período de latência, período onde se consolidam as principais aquisições culturais sobretudo por meio dos processos educacionais.

Para Lacan ([1972-1973]/1985) falar de sexuação é tratar da sexualidade, que é uma organização simbólica formada por uma complexa rede de significantes lançada ao sujeito nos primeiros anos, e não apenas a assunção do sexo biológico. A sexuação vai sendo constituída pelo imaginário do sentido conferido pelo simbólico e pelo real da diferença anatômica dos sexos. Por meio do Ideal de Eu, o sujeito elabora a construção simbólica da masculinidade e da feminilidade. Assim só podemos pensar nas posições, masculina e feminina, como gêneros que se estabelecem na ordem simbólica, por meio dos significantes da linguagem. Para tornar-se menino, não basta ter o pênis, é preciso que o campo da linguagem venha dotá-lo de atributos fálicos, o que permitirá que ele se posicione no campo da masculinidade. Daí por que nos indivíduos com vigorexia aparecerem identificações no plano das aspirações do Ideal do $\mathrm{Eu}$, a significantes que remetem ao masculino. Segundo Pope (2000), Feitosa Filho (2008), no discurso dos indivíduos com vigorexia, comparece fortemente ideais como: ser aceito, ser amado, ser reconhecido, ser forte, musculoso, agressivo, poderoso, bem-sucedido, ativo, etc.; isso significa ser detentor do que em psicanálise consideramos significantes fálicos. É por meio da identificação com esses atributos que o simbólico recobre o imaginário do sujeito. Esses ideais culturais vêm mostrar para o sujeito alguns pontos a partir dos quais ele pode ser amado e reconhecido pelo Outro. No caso dos indivíduos com sintomas vigoréxicos, se constituem como pontos pelos quais sua identidade fálica pode ser aspirada e, de certa forma possa fazer frente à castração: assinalando no corpo, por meio de sua musculatura, a inscrição simbólica desse conjunto de significantes. Assim, quando o corpo é tomado enquanto objeto pela libido do Eu ele assume a significação do falo.

Nos sintomas vigoréxicos o que anima o desejo do sujeito está ligado à falta e não ao ter o falo, pois de fato o sujeito masculino pode até tê-lo (o pênis), mas não pode sê-lo, uma vez que a castração incidiu e aponta para o vazio, a falta-a-ser constituinte. Pela via imaginária "malhar" significa produzir músculo tumescido, tal qual o pênis ereto, sendo também uma atividade produtora do suor, do gemido, na descarga de prazer que há no grito ao exercitar e levar ao limite a potência do músculo de forma e finalmente relaxar; tudo isso só pode evocar a própria relação sexual. $\mathrm{O}$ ato de "malhar" pode ser considerado como um substituto de uma relação sexual, pois em muito se assemelha à masturbação, ou seja, parece ser um prazer autoerótico em que o indivíduo toma o próprio corpo como objeto de investimento levando-o até os limites suportáveis de tumescimento, tal como acontece na ereção de um pênis, para, em seguida, produzir certo relaxamento e detumescência. O que o indivíduo com sintomas vigoréxicos não suporta é a detumescência do órgão, pois esta aponta para a castração $(-\varphi)$, da qual ele nada quer saber. Ora, o grande problema é que a castração é ela própria uma experiência incessantemente renovada no ser falante, impondo a divisão e a impossibilidade de completude.

A problemática dos sintomas vigoréxicos está relacionada assim, ao posicionamento do sujeito diante da questão fálica e da sexuação. O sujeito com sintomas vigoréxicos procura não ter a identidade fálica questionada. Entretanto, ter um pênis, por si só não garante que o indivíduo com sintomas vigoréxicos se sinta possuidor do falo, tendo em vistas que o falo, em sua dimensão simbólica, foi aquilo ao qual sujeito teve que renunciar enquanto identificação imaginária na travessia edípica (ser o falo) aceitando a castração. Essa função do falo enquanto castração convoca sempre à busca de um termo x para compensar a perda 
de gozo, estamos aqui na dimensão do 'ter o falo'. O falo aparece então, enquanto objeto que pode ser substituído por outros objetos (significantes) para compensar esse déficit de gozo, que no caso do indivíduo com sintomas vigoréxicos será por meio do corpo hipertrofiado; podemos afirmar então que os indivíduos com sintomas vigoréxicos buscam assinalar simbolicamente, inscrevendo no real do corpo, por meio da forte e grande musculatura, a manutenção imaginária do falo.

\section{O Especular e a Esquize do Sujeito nos Sintomas Vigoréxicos}

Diferentemente das demais pulsões, orais e anais, a pulsão escópica não está ligada a uma fase, ela está sempre presente e é perceptível na criança por meio da pulsão de saber. Freud (1910/1996) percebeu que as curiosidades sexuais infantis estão relacionadas ao saber sobre o enigma da diferença sexual, ou seja, sobre a castração. Freud (1923/1996e) assinala a importância da pulsão escópica quando postula que é por meio da percepção visual da ausência de pênis nas mulheres que se estabelece as coordenadas da relação do sujeito com a realidade. É por meio da visão, portanto que algo do campo da falta é percebido pela criança.

Seguindo a lógica do olhar, do ser olhado e do dar-se a ver, a academia de musculação tornou-se o templo sagrado do culto narcísico do corpo. Ela se constitui como um lugar hierarquizado, disciplinado, com uma ética de trabalho (trabalho do corpo). Ela é também um lugar erotizado, onde a potência viril, fálica, é colocada em evidência; importa oferecer-se ao olhar do outro de forma reduplicada, pois há espelhos por todos os lados para que cada um possa melhor contemplar a si e contemplar o corpo do outro, conclamando a um mostrar-se. Assim a academia torna-se um locus privilegiado para o exercício da pulsão escópica. Nela fica evidente o quanto o olhar aparece, não apenas como órgão da visão, mas em toda sua potência libidinal mediante o par olhar-ser olhado. O olhar enquanto objeto pulsional de que trata a psicanálise não diz respeito ao sujeito da percepçãorepresentação, esfera consciente do indivíduo, mas um olhar que incide sobre o sujeito tornando-o objeto percebido; é, dessa forma, um dos suportes do desejo inconsciente do Outro, uma vez que o sujeito é afetado por este olhar buscando se situar como objeto de desejo do Outro. A este olhar o sujeito procura responder ao Che vuoi? Questão fundamental por se referir ao desejo, que desde o estádio do espelho aparece como desejo do Outro.

No Seminário 11 Lacan (1964/1988) mostra que a percepção visual é da ordem do imaginário, registro estruturado e sustentado pelo simbólico de tal forma que "a estrutura da linguagem condiciona tanto o sujeito que percebe quanto o que ele percebe." (Quinet, 2002, p.38). A vontade de gozo da qual o estádio do espelho é o paradigma não pode trazer ao indivíduo senão a decepção posto remeter-se a um ser alienado ao outro na relação imaginária, uma vez que o eu é constituído pela imagem do outro no espelho; assim, não pode haver justa equivalência por esta imagem não ser o próprio sujeito, mas uma projeção. Resta ao indivíduo certa oscilação que pode ser geradora de angústia em relação à imagem. A imagem do corpo, na medida em que ela fornece uma Gestalt, fixa uma estatura que pode ser percebida pelo olho como totalidade, um todo que escamoteia a falta. Entretanto ocorre que não há coincidência entre essa estatura apreendida pelo sujeito da representação e sua forma real. Há uma esquize, divisão do sujeito que é o próprio encontro falho com o real, com a castração, que deixa o indivíduo em déficit em relação à sua imagem.

Podemos tentar recompor os tempos dessa dialética, que vai da percepção da imagem total à oferta que o sujeito faz dela. A imagem é total, e, em relação a ela, o sujeito sente-se em déficit. Essa imagem, ainda que seja a dele mesmo, é Outra, pois ela é total e ele é incompleto. Sob esse aspecto, é a imagem do Outro, porque é Outra. Por essa razão falta ao sujeito alguma coisa, mas ao Outro também. (Miller, 2005, p. 309)

Quinet (2002) aponta que "No âmbito escópico, do desejo, o sujeito se dá-a-ver para o Outro, se oferece em exibição ao Outro do desejo, se mostra ao desejo do Outro" (p.70). Mas, o que supostamente teria o indivíduo com sintomas vigoréxicos a oferecer ao olhar do Outro? No plano do imaginário, a ilusão da beleza, que se articula com o campo escópico. A beleza é aquilo que o sujeito do desejo dota de atributos no outro, assim, ela atrai, excita, é, portanto a pulsão escópica que dota um objeto de beleza. A perfeição do corpo produz júbilo ao individuo e é capaz de despertar o desejo no outro, assim por meio de sua beleza o indivíduo se posiciona como suposto objeto capaz de funcionar como causa do desejo para o outro. Lacan situa a beleza como engodo, como aquilo que funciona como um véu que encobre a castração.

É preso nessa dimensão do belo que acredita satisfazer a condição do olhar que a provoca, que o indivíduo com sintomas vigoréxicos de um lado, deseja dar-se a ver pela sua musculatura, tentando responder ao que ele supõe ser o desejo do Outro, entretanto essa imagem é geradora de angústia quando desvela a falta constitutiva do sujeito, pois ele não consegue se oferecer senão reduzido enquanto objeto $a$, pois que este é o resto da operação simbólica promovida pela Lei. A angústia surge quando se assinala o lugar da falta mediante a qual o indivíduo é tomado pela vergonha 
de não se sentir suficientemente grande, forte, havendo uma queda da identificação fálica. Ora, a esquize do olho e do olhar evidencia a dissimetria entre o que é visto e a forma como o sujeito o percebe no ser humano que se manifesta em sua plenitude nos sintomas vigoréxicos.

Assim, podemos dizer que há uma dissimetria fundamental no fenômeno perceptivo na qual o sujeito comparece não como sujeito da percepção, mas como sujeito do desejo, e essa discordância fundamental ocorre em todos os seres humanos, não apenas nos indivíduos com sintomas vigoréxicos. Em se tratando dos sintomas vigoréxicos, o sujeito da percepção, indiviso, deveria ser capaz de enxergar a própria gigantesca forma muscular, no entanto esta fica elidida pelo sujeito do desejo, por se achar ainda insuficientemente grande/musculoso. Resta ao indivíduo a insatisfação em relação à própria imagem. Sabemos que a defesa se ergue para evitar a aproximação relacionada ao desejo incestuoso (ser o complemento da falta materna).

Temos nos sintomas vigoréxicos em sua preocupação exacerbada do individuo com a aparência do corpo algo da ordem de um retorno do olhar como destino da pulsão escópica, na qual o sujeito ao dar-se-a-ver faz com que a pulsão retorne ao eu, provocando uma dissimetria na qual - a vergonha por ter um corpo pequeno - remete ao retorno do olhar do outro sobre o sujeito, evidenciando a castração; olhar que pode ser visto ou imaginado, e que, deixa como resto um afeto de angústia que promove uma perda dos pontos de referência imaginários do sujeito. Esse olhar está ligado ao circuito da pulsão escópica e afeta o sujeito quando se satisfaz de forma paradoxal nos sintomas; entretanto convém assinalar que a angústia despertada pela imperfeição do corpo é o que protege o sujeito de gozar de um corpo perfeito que o remeteria aos perigos da relação incestuosa; esse olhar, enquanto retorno de gozo provém em última instância do olhar paterno, representado pelo Supereu. $\mathrm{O}$ que deveria ser uma experiência do desejo retorna como barreira à sua realização, de um lado o Supereu convida a ver o espetáculo do corpo ao mesmo tempo em que o proíbe de todo o júbilo. Para dar conta da angústia o sujeito tentará responder pela imagem narcísica através da fantasia, mediante a busca a tamponar a falta conquistando um corpo perfeito. Por outro lado, o Supereu proíbe o mesmo ato via consciência crítica, pois o gozo que é colocado em jogo é autoerótico, o da masturbação do corpo (referente ao desejo incestuoso), esse gozo é sentido como perigoso e deve ser castigado pelo Supereu, o exibicionismo do mostrar-se que deveria ser motivo de júbilo para o sujeito é barrado sob a ameaça de castração, trazendo o mal-estar ao sujeito diante da própria imagem.

O que pode ser observado nos indivíduos com sintomas vigoréxicos é que a falta imaginariamente tamponada pela

saturação do olhar sobre a superfície corporal gigantesca é surpreendida pela angústia de não estar à estatura desejada. Assim, a compulsão ao exercício, as dietas e o uso dos esteróides, são uma manifestação paradoxal dos imperativos do Supereu tentando remediar a falta desvelada.

\section{Os sintomas vigoréxicos e o mal-estar na cultura}

Sabemos que o imaginário é o campo da identificação especular com o outro. Nesse plano, as imagens apelam à identificação mais direta com a imagem do corpo e chegam ao indivíduo como imperativos de ideais a serem seguidos e é essa medida que permite que os modos de gozo possuam uma relatividade histórica, por estarem referidos ao Outro, ao ideal cultural. Esses corpos se tornam atraentes, na medida em que escamoteiam a castração, pois parecem exibir vigor, saúde, certo hedonismo e veiculam a ideia de bom desempenho. "É o lugar de onde o sujeito aguarda um olhar de amor, o reconhecimento de seu valor, a admiração, aplausos" (Quinet, 2002, p. 118).

Lacan (1970/1992) criou a teoria dos discursos para dar conta daquilo que chama de laço social. O discurso se funda na estrutura de linguagem, e, portanto, na estrutura do significante. Sabendo que o inconsciente está estruturado como linguagem, o discurso é efeito da cadeia significante. Baseado em o "Mal-Estar na Civilização", onde Freud (1930/1996) aponta o relacionamento com os outros homens como uma das causas de sofrimento do homem, neste Seminário o mal-estar na civilização é encarado como o mal-estar dos laços sociais. É por meio dos discursos que o homem faz laço social. O mal-estar está representado nos discursos como elemento heterogêneo, como objeto a, representando a parte excluída da linguagem e aquilo que a

Discurso do mestre

$$
\frac{\mathrm{s}_{1}}{\$} \underset{\mathrm{II}}{\rightarrow} \frac{\mathrm{s}_{2}}{a}
$$

Discurso da bistérica

$$
\frac{\$}{a} \underset{\|}{\rightarrow} \frac{\mathrm{S}_{1}}{\mathrm{~S}_{2}}
$$

Figura 1. Os quatro discursos

Fonte: Lacan, J. (1992). O Seminário 17: O avesso da psicanálise. Rio de Janeiro: Zahar. (Originalmente publicado em 1970). 
civilização exige que o homem renuncie, isto é, os objetos de suas pulsões. A esse objeto (a) Lacan denominará objeto mais-gozar. Os discursos partem do que Lacan denominou discurso do Mestre. Este é o discurso que ordena, que age por meio de injunções e imperativos.

Uma leitura possível para os sintomas vigoréxicos a partir da teoria dos discursos proposta por Lacan nos aponta que os significantes mestres (S1) são os significantes privilegiados pelo sujeito em sua relação com a cultura: ser forte, vencedor associados a imagem do corpo musculoso. Assim essas discursividades (S1) presentes nos ideais culturais contemporâneos atuam como injunções, ordenamentos, fornecem significantes que põem o individuo com sintomas vigoréxicos para trabalhar, fazendo com que estes busquem saberes no campo do Outro (S2) que possam responder à essa demanda; esses saberes estão representados nos discursos pelo saber fazer contido nas dietas, pela quantidade de horas de treino, pelo número de séries de repetições, pelo uso de anabolizantes, etc. Entretanto o resultado desse cálculo do desejo se mantém fadado ao fracasso (a) como quantidade que o sujeito (\$) não consegue contabilizar, esse é o mais-gozar sentido pelo sujeito como déficit, déficit de gozo. Dada a insatisfação resultante, essa estrutura exige sempre um trabalho a mais que faz com que o gozo retorne e ponha novamente o vigoréxico a trabalhar, a exigir mais trabalho do corpo. Esse circuito repetitivo do gozo leva, muitas vezes, ao que Pope (2000) qualificou como overtraining: fadiga generalizada devido o excesso de treinamento, que muitas vezes expõe às lesões, pondo em risco a saúde do corpo, evidenciando a face mortífera do sintoma.

Há no indivíduo com sintomatologia vigoréxica uma vigilância dos imperativos do Supereu que funcionam, muitas vezes como discurso do mestre levando o sujeito não apenas à adição ao exercício, mas também a uma compulsão em medir-se (é preciso medir, quantificar para se certificar, deve haver uma certeza que funcione como uma verdade), entretanto os valores nunca serão suficientes, há sempre uma perda (perda de gozo) que faz o indivíduo com sintomas vigoréxicos se julgar sempre aquém do ideal $(-\varphi)$; aí estarão seus problemas de autoestima que o farão sempre desqualificar a própria imagem. Os resultados obtidos estarão sempre em descompasso em relação às exigências de perfeição do eu ideal, fixado numa certa megalomania. Assim, podemos dizer que no indivíduo com sintomas vigoréxicos a compulsão é da ordem do imperativo de satisfazer o Supereu, enquanto o desejo é da ordem do reconhecimento e do amor, é, portanto, uma demanda endereçada ao Outro.

Em muitos casos apontados por Pope (2000) o sujeito não consegue controlar o ímpeto em "malhar"; há algo no campo do Supereu que pressiona fazendo com que o sujeito transgrida as próprias proibições, exigindo um gozo pulsional que traz junto o sentimento de culpa. Esse gozo está para além do princípio de prazer, evidenciando a pulsão de morte, onde, muitas vezes, a própria saúde do corpo é posta em risco em nome do excesso e da compulsão ao exercício, ao aumento de exigências de trabalho do corpo. Há no próprio ato de "malhar" uma repetição prescrita nos programas de condicionamento físico, que funcionam como injunções para o indivíduo, pois exigem um trabalho segmentado sob determinados grupamentos musculares, que funcionam como zonas erógenas. Há um verdadeiro primando pela repetição, exigida para se obter a definição muscular e/ou um aumento das cargas de peso para obtenção de massa muscular e/ou definição.

Apoiados numa leitura dos matemas dos Quatro discursos podemos dizer que o impossível da satisfação que reside na disjunção entre o sujeito (\$) e o objeto (a), entre o sujeito e o corpo produzido, representado pela dupla barra (//) que separa, protege os mesmos. É na tentativa de tamponar esse furo que emerge a fantasia, permitindo ao sujeito se engajar nas suas relações com os objetos $(\$ \diamond \mathrm{a})$ articulando a ordem inconsciente com o imaginário; graças à fantasia o sujeito está protegido em relação ao gozo, ainda que esta seja entendida como reserva de gozo matriz dos sintomas.

Lacan (1972 -1973) salienta que, dada a castração, o gozo está fora da possibilidade humana, por ser um atributo do pai morto, restando ao sujeito gozar por meio dos sintomas ou pelo viés da fantasia. Não resta outra coisa ao indivíduo senão aceitar o sacrifício do gozo em favor da vida e da civilização. A fantasia será, pois, uma tela protetora, uma construção simbólico-imaginária do sujeito que permite sua relação com o mundo externo (realidade) e com o semelhante no marco do laço social. O neurótico é aquele que busca se defender desse gozo absoluto desmesurado, que relembra a vivência mítica do incesto. Se o gozo absoluto se mostra num horizonte impossível do qual o sujeito se defende, o neurótico encontra duas formas de refreá-lo, gozando parcialmente, com as fantasias (mais-gozar) e os sintomas (gozo fálico). No momento em que progride a análise dos sintomas na experiência psicanalítica, têm-se acesso às fantasias que a eles subjazem e aos significantes em que estão ancoradas, de forma que podemos encontrar algo em comum nestas, uma certa monotonia da fantasia, que não cessa de se repetir e que em última instância está relacionada à fantasia fundamental. As fantasias estão relacionadas à formação de sintomas, uma vez que,

[...] Todos os objetos e tendências que a libido abandonou, ainda não foram abandonados em todos os sentidos. Tais objetos e tendências, ou seus derivados, ainda são 
mantidos, com alguma intensidade, nas fantasias. Assim, a libido necessita apenas retirar-se para as fantasias, a fim de encontrar aberto o caminho que conduz a todas as fixações reprimidas. (Freud, 1996 [1916 - 1917], p.436)

Essas fantasias, por conterem esse supertivamento sexual, serão geradoras de angústia (excesso de afeto) e estão sujeitas ao recalque, sendo, portanto, uma formação que permanece inconsciente e que pressiona no sentido de obterem satisfação. A angústia não provém do processo de recalcamento, mas do agente recalcador; ela advém como reação a um perigo pressentido pelo Eu e, nesse processo, o sintoma é formado para evitar o surgimento do estado de angústia. Por ser gerador de angústia, dificilmente se reconhece que o sintoma é uma forma de satisfação e que sua realização se apresenta como uma compulsão à repetição que trabalha num sentido de reeditar antigas formas de satisfação que se fixaram em experiências traumáticas e situações infantis. O sintoma será, portanto, o substituto de uma satisfação pulsional, uma forma de satisfação da fantasia inconsciente que teve sua origem na sexualidade infantil, estando portanto ligada aos significantes que norteiam a vida do individuo. O sintoma é "o significante de um significado recalcado da consciência do sujeito" (Lacan, 1998 [1953 - 1954], p. 282). Aprendemos com Freud que o cerne de tudo que é recalcado está relacionado ao complexo de castração (Lacan, 1999 [1957-58]). A verdade do sintoma está ligada ao Édipo, na medida em que o sintoma expressa a realidade do incurável da castração, que produz a divisão do sujeito. O sintoma está, portanto, remetido aos significantes originários do Outro, daquele Outro que serviu de suporte na constituição do desejo do sujeito. De forma que "O não sepultado pela castração é o que retorna da repressão sob a forma de sintomas, monumentos que comemoram o gozo abandonado, ainda que transposto também, de outra maneira, nos termos linguageiros. Os sintomas são traduzíveis, interpretáveis, efeitos de 'conversão' do gozo (a que sempre remeterão), formas também elas de gozo fálico." (Braunstein, 2007, p.70)

Freud (2007b/1923) nos diz que os sintomas são os derivados do recalcado, são seus representantes perante o Eu, sendo o recalcado um território estrangeiro ao Eu. Dada sua aspiração à síntese, o Eu procura integrar o sintoma à sua organização, evitando que este permaneça isolado. Se, inicialmente, o sintoma é percebido como um "corpo estranho" ou "hóspede indesejável", em seguida, o Eu tenta reconhecer e fazer uma adaptação ao sintoma e, de certa forma, tirar o máximo de proveito possível dele, assim o Eu se identifica com o sintoma. Freud apontou as dificuldades da remoção dos sintomas, bem como a prudência diante de um furor curandis por parte do psicanalista porque eles, os sintomas, representam uma formação de compromisso entre o recalcado e a instância recalcadora e trazem benefícios secundários, que no caso da vigorexia são da admiração do Outro, já que este consegue atender aos ideais culturais pela forma adquirida, não apenas esteticamente, mas relativas também ao campo simbólico que portam enquanto sugnificantes, isso torna esses individuos bastante resistentes a reconhecer a falta, o sofrimento. Dessa forma apresentam tanto um ganho primário ligado às formas de satisfação da pulsão, como são portadores de satisfações secundárias existentes na relação do indivíduo com a cultura. Assim, o sintoma pode ser compreendido então como uma forma de laço social do sujeito sendo a resposta do mesmo ao mal-estar na cultura.

Pesquisadores contemporâneos têm apontado que o individuo: "condenado ao esgotamento pela falta de uma perspectiva revolucionária, ele busca na droga ou na religiosidade, no higienismo ou no culto de um corpo perfeito o ideal de felicidade impossível." (Roudinesco, 2000, p.19). Incapaz de se engajar em projetos sociais mais amplos, resta o investimento narcísico em si mesmo, e, nesse processo, toma-se imaginariamente o corpo como lugar privilegiado, pois que o Eu é, sobretudo uma projeção da superfície corporal (Freud, 1923/2007b), sendo o efeito da emergência do corpo próprio. Se o Eu é uma instância de superfície, o que o indivíduo com sintomas vigoréxicos mostra é o engodo sintomático de uma busca por delimitar a superfície de seu corpo, onde se articulam dois desejos contraditórios: o aumento da superfície corporal e sua definição enquanto posições inversas. Ora, são duas propostas paradoxais, porque um aumento nessa superfície vai sempre exigir um reinvestimento na definição. A definição joga com a fixidez na estatura, melhor delimitando a superfície, ao mesmo tempo em que é demandado um constante aumento nessa mesma estatura, sendo de partida impossível uma satisfação com a forma do corpo que retornará sempre como resto insatisfeito.

\section{Considerações Finais}

Vigorexia é um termo cunhado no campo da Psiquiatria que, ao dar conta da entrada em cena desse novo "malestar" na cultura, apressou-se em tentar defini-lo e isolálo em suas características sintomáticas, pretendendo, com isso criar uma nova categoria nosográfica - o transtorno dismórfico muscular. Como foi apontado no artigo, a etiologia dos sintomas desses indivíduos emerge da dissimetria fundamental entre o olho e o olhar, dissimetria que é comum a todos os seres humanos. Essa ideia se afasta da patologização dos indivíduos e da necessidade de criação de novas categorias nosográficas, pois acreditamos que, nesses casos, os sintomas estejam emergindo como meios de gozo em resposta ao mal-estar na cultura. Reconhecemos 
que por meio do estudo aqui proposto não caberia uma discussão relativa ao diagnóstico estrutural, uma vez que este só pode ser feito em cada caso (estudo de caso), de modo que a perspectiva adotada foi interrogar apenas os sintomas que comparecem como universal na vigorexia.

Os sintomas vigoréxicos podem ser considerados como expressão do mal-estar na cultura, manifestação do real de gozo, que retornam como respostas do sujeito aos ideais civilizatórios que exigem a renúncia do gozo. O que vem ferir a onipotência do eu, esta espécie de "eucracia", que a contemporaneidade conhece tão bem, e apontar um mal-estar que o sujeito não consegue deter é o sintoma. O sintoma é que o obriga a procurar uma análise para dar conta dessa angústia que provém do gozo. "O gozo existe por causa do significante e à medida que o significante não o detenha e o submeta à sua ordem que é a norma fálica. A linguagem é o que funciona como barreira a um gozo que não existiria sem ela" (Braunstein, 2007, p. 77).

APsicanálise se utilizará da escuta dos traços estruturais do sujeito que, por meio da associação livre, que coloca o sujeito numa posição histericizante (\$), relativa ao discurso da histérica; assim ele é capaz de produzir um sintoma analítico, mediante suas interrogações, suas queixas sobre a causa de seu mal-estar (a) endereçadas ao outro (S2), permitindo uma reconstrução de sua história, da história de seus significantes (S1), no sentido de passar esse sintoma à cifra de gozo por meio da palavra. A linguagem traça as vias de gozo do sujeito pelo significante, esses significantes (mestres, $\mathrm{S} 1$ ) aos quais o sujeito se encontra identificado. O propósito da análise deve ser passar o gozo à contabilidade possibilitando uma mudança operada na economia de gozo do sujeito. Essa mudança se efetua na relação entre o significante e o gozo, uma vez que o significante é causa do gozo. A partir da escuta dessa singular sintomatologia a perspectiva psicanalítica tornar-se-á capaz de apresentar uma teoria explicativa sobre sua etiologia, refutando ou comprovando as hipóteses ora lançadas nesse estudo.

A perspectiva psicanalítica pode ser uma teorização capaz de apresentar uma hipótese explicativa sobre os sintomas da vigorexia enquanto forma de mal-estar e propor uma clínica. A psicanálise não irá buscar suas respostas nas neurociências onde reina a crença em pré-disposições genéticas ou em alterações neuroquímicas. A psicanálise cria condições de pensar o surgimento de categorias como a vigorexia a partir da estória e da História na medida em que articula o sintoma enquanto resposta de cada sujeito às demandas do Outro, relacionando-o à história de sua época e de seus significantes.

\section{Referências}

Baudrillard, J. (1970). A sociedade de consumo. São Paulo: Martins Fontes.

Braunstein, N. (2007). Gozo. São Paulo: Escuta.

Courtine, Jean-Jacques, \& Denise Bernuzzi Sant'Anna. (2005). Os Stakhanovistas do narcisismo: Bodybuilding e puritanismo ostentatório na cultura americana do corpo. Políticas do corpo (pp. 81-114). São Paulo: Estação Liberdade.

Debord, G. (2002). A sociedade do espetáculo. Rio de Janeiro: Contraponto.

Feitosa Filho, O. (2008). Vigorexia: uma leitura psicanalítica. (Dissertação de Mestrado não publicada) Universidade Federal do Ceará.

Freud, S. (1996a). Notas psicanalíticas sobre um relato autobiográfico de um caso de paranóia (dementia paranoides). In Edição Standard Brasileira das Obras Psicológicas Completas (vol. 12, pp. 419-440). Rio de Janeiro: Imago. (Original publicado em 1911)

Freud, S. (1996b). Organização genital infantil: uma interpolação na teoria da sexualidade. In Edição Standard Brasileira das Obras psicológicas Completas de Sigmund Freud (vol. 19). Rio de Janeiro: Imago. (Originalmente publicado em 1923)

Freud, S. (1996c). Leonardo da Vinci e uma lembrança da sua infância. In Edição Standard Brasileira das Obras Psicológicas Completas de Sigmund Freud (vol. 11). Rio de Janeiro: Imago. (Originalmente publicado em 1910)

Freud, S. (1996d). O mal-estar na civilização. In Edição Standard Brasileira das Obras Psicológicas Completas de Sigmund Freud (vol. 21). Rio de Janeiro: Imago. (Originalmente publicado em 1930)

Freud, S. (1996e). Os caminhos da formação dos sintomas. In Edição Standard Brasileira das Obras Psicológicas Completas (vol. 16). Rio de Janeiro: Imago. (Original publicado em 1917)

Freud, S. (2007). O Eu e o Id. In Escritos sobre a psicologia do inconsciente (vol. 3). Rio de Janeiro: Imago. (Originalmente publicado em 1923)

Freud, S. (2011). A moral sexual "cultural" e o nervosismo moderno. In N. Braunstein, \& B. Fuks (Orgs), 100 anos de novidade. A moral sexual "cultural" e o nervosismo moderno de Sigmund Freud [1908 - 2008]. Rio De Janeiro: Contra Capa. (Originalmente publicado em 1908) 
Lacan, J. (1985). O Seminário 20: mais, ainda. Rio de Janeiro: Jorge Zahar Editor. (Originalmente publicado em 1972-1973)

Lacan, J. (1988). O Seminário 11: os quatro conceitos fundamentais da psicanálise (2a.ed). Rio de Janeiro: Zahar. (Originalmente publicado em 1964)

Lacan, J. (1998a). O estádio do espelho como formador da função do eu. In Escritos. Rio de Janeiro: J. Zahar. (Originalmente publicado em 1966)

Lacan, J. (1998b). O Seminário livro 1: Os escritos técnicos de Freud. Rio de Janeiro: J. Zahar. (Originalmente publicado em 1954)

Lacan, J. (1992). O Seminário 17: O avesso da psicanálise. Rio de Janeiro: Zahar. (Originalmente publicado em 1970).

Lacan, Jacques. (1995). O Seminário livro 2: O eu na teoria de Freud e na técnica da psicanálise (4a. ed). Rio de Janeiro: Zahar. (Originalmente publicado em 19541955)

Lacan, Jacques. (1999). O Seminário 5: As formações do inconsciente. Rio de Janeiro: J. Zahar. (Originalmente publicado em 1957-1958)

Miller, J-A. (2005). Silet: os paradoxos da pulsão de Freud a Lacan. Rio de Janeiro: Zahar.

Pope, H. G., Jr., Katz, D. \& Hudson J. (1993). Anorexia nervosa and "reverse anorexia" among 108 male bodybuilders. Comprehensive Psychiatry. 34(6), 4069.

Pope, H. G., Jr. (2000). O complexo de Adônis: a obsessão masculina pelo corpo. Rio de Janeiro: Campus.

Quinet, A. (2002). Um olhar a mais. Rio de Janeiro: J. Zahar.

Roudinesco, E. (2000). Por que a psicanálise?. Rio de Janeiro: J. Zahar.

Severiano, M. F. V., Rêgo, M., \& Montefusco, E. V. R. (2010). O corpo idealizado de consumo: paradoxos da hipermodernidade. Revista Mal Estar e Subjetividade, 10(1), 137-165. Recuperado em 19 de setembro de 2014, não é preciso informar a data de acesso de http://pepsic.bvsalud.org/scielo.php?script=sci arttext\&pid $=$ S1518-61482010000100007\&lng=pt\&tln $\mathrm{g}=\mathrm{pt}$.

Vasconcelos, J. (2013, Dez). Vigorexia: quando a busca por um corpo musculoso se torna patológica. Revista Educação Física UNIFAFIBE, 2(2), 91-97. Recuperado em 19 de setembro de 2014, não é preciso informar a data de acesso de https://www.unifafibe. com.br/revistasonline/arquivos/revistaeducacaofisica/ sumario/29/16122013151946.pdf.

\section{Endereço para correspondência:}

Odimar A. Feitosa Filho

Endereço: Rua Professor Dias da Rocha, 500, apto 140 Meireles - Fortaleza-CE - Cep: 60.170-310

E-mail: odimarfeitosan@hotmail.com 
